Jurnal Ilmiah Kesehatan Sandi Husada
https://akper-sandikarsa.e-journal.id/JIKSH
Volume 10| Nomor 2| Desember|2021
e-ISSN: 2654-4563 dan p-ISSN: 2354-6093
DOI: 10.35816/jiskh.v10i2.619

\title{
Faktor yang Memengaruhi Kepatuhan Imunisasi Tetanus Toksoid Ibu Hamil
}

Musfirah Musfirah' ${ }^{1}$, Muhammad Rifai ${ }^{2}$, Abdul Kadir Kilian ${ }^{\mathbf{3}}$

${ }^{1,2,3}$ Fakultas Kesehatan Masyarakat, Sekolah Tinggi Ilmu Kesehatan Tamalatea Makassar

\begin{tabular}{|c|c|}
\hline Article Info & Abstract \\
\hline $\begin{array}{l}\text { Key words: } \\
\text { Imunisasi; } \\
\text { Sikap; } \\
\text { Petugas kesehatan; } \\
\text { Akses; } \\
\text { Dukungan suami; }\end{array}$ & 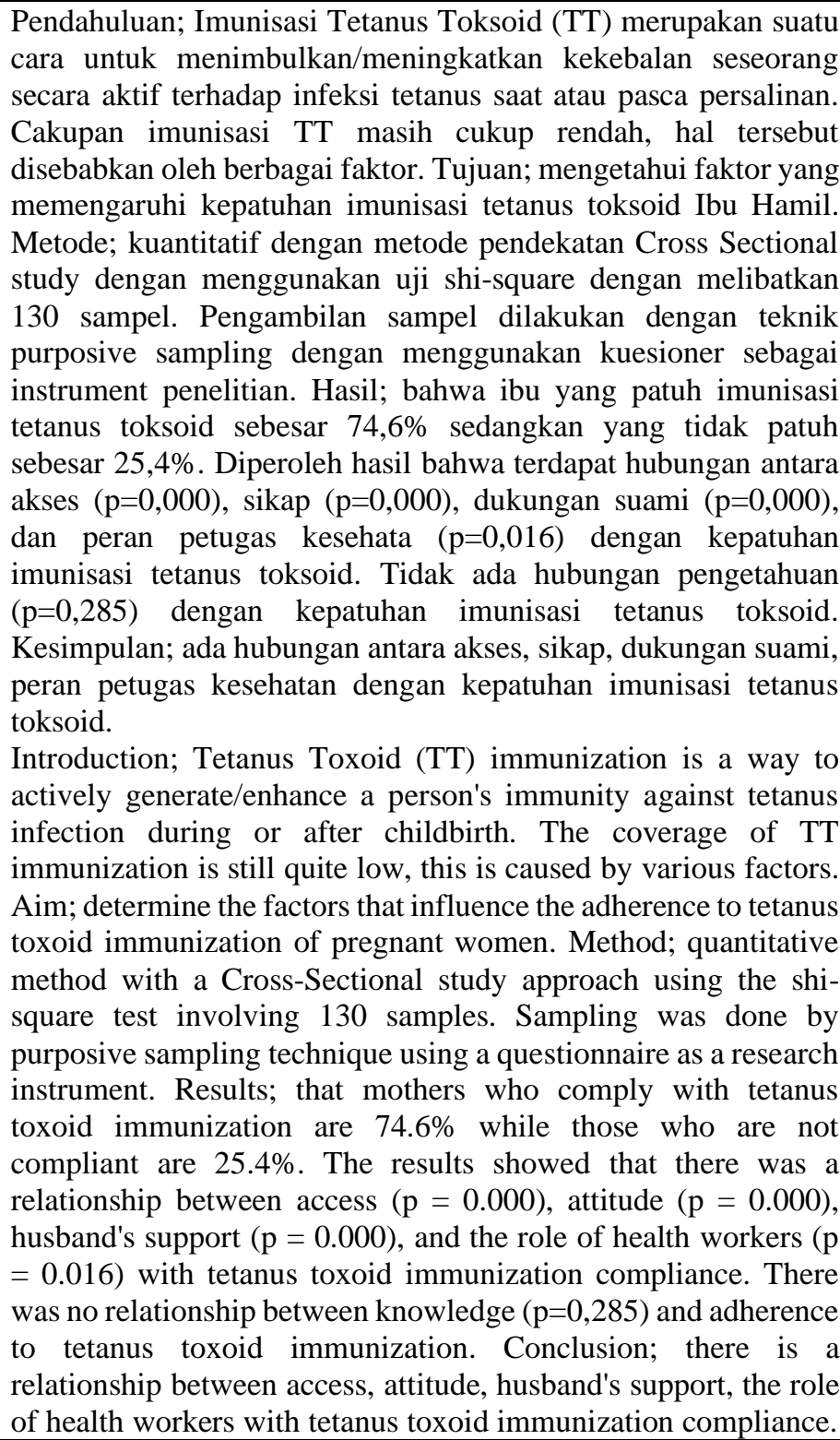 \\
\hline $\begin{array}{l}\text { orresponding author } \\
\text { nail }\end{array}$ & $\begin{array}{l}\text { sfirah Musfirah } \\
\text { firah@ @stiktamalateamks.ac.id }\end{array}$ \\
\hline
\end{tabular}

\section{Pendahuluan}

Pembangunan kesehatan diarahkan untuk meningkatkan kesadaran, kemauan, dan kemampuan hidup sehat bagi setiap orang agar meningkatnya derajat kesehatan masyarakat yang 
Jurnal Ilmiah Kesehatan Sandi Husada

Volume 10 Nomor 2 Desember 2021

setinggi-tingginya dapat terwujud. Pembangunan kesehatan diselenggarakan berdasarkan pada perikemanusiaan, pemberdayaan dan kemandirian, adil dan merata serta bermanfaat dengan perhatian khusus pada penduduk rentan, antara lain ibu, bayi, anak, lanjut usia (lansia), dan keluarga miskin (Suryati, 2015).

Menurut WHO dan UNICEF sebelum tahun 2000 di seluruh dunia ada sebanyak 135 negara yang sudah mencapai eliminasi Tetanus Maternal dan Neonatal (TMN). Hingga akhir tahun 2009 sudah 151 negara yang mencapai eliminasi TMN, dan 42 negara belum mencapai eliminasi TMN. Per Desember 2010 masih terdapat 38 negara yang belum mencapai eliminasi TMN, terutama berada di Afrika dan Asia. Hingga Februari 2012, masih terdapat 34 negara yang belum tereliminasi TMN. Badan Kesehatan Dunia (WHO) kembali mengajak negara-negara berkembang untuk mencapai target Eliminasi Tetanus Maternal dan Neonatal (ETMN) pada tahun 2005. Pada tahun 1988, WHO memperkirakan bahwa sebanyak 787,000 bayi baru lahir meninggal akibat Tetatus Neonatal (TN). Sehingga pada akhir tahun 1980-an perkiraan angka kematian tahunan global TN adalah sekitar 6,7 kematian per 1000 kelahiran hidup, jelas ini merupakan masalah kesehatan masyarakat yang penting (Kemenkes RI, 2012).

Menurut (Depkes RI, 2010), Imunisasi adalah suatu cara untuk meningkatkan kekebalan seseorang secara aktif terhadap suatu penyakit tersebut tidak akan sakit atau sakit ringan. Imunisasi merupakan tindakan preventif yang diperlukan untuk meningkatkan derajat kesehatan masyarakat dan mempertahankan status kesehatan seluruh rakyat. Imunisasi tetanus toksoid adalah proses untuk membangun kekebalan sebagai upaya pencegahan terhadap penyakit tetanus. Untuk mencegah Tetanus Neonatal (TN) Ibu Hamil harus mendapatkan imunisasi tetanus toksoid, sehingga ibu sudah memiliki antitoksin tetanus dalam tubuh ibu yang akan ditransfer melalui plasenta yang akan melindungi bayi yang akan dilahirkan dari penyakit tetanus. Sedangkan Imunisasi adalah memberi kekebalan terhadap penyakit tertentu dan mencegah terjadinya penyakit tertentu dan pemberiannya bisa berupa vaksin.

Salah satu kelompok berisiko adalah Ibu Hamil (Bumil) yang menjadi salah satu prioritas pemerintah termasuk mengatur soal pemberian imunisasi selama kehamilan. Imunisasi adalah suatu cara untuk menimbulkan/meningkatkan kekebalan seseorang secara aktif terhadap suatu penyakit tersebut tidak akan sakit atau sakit ringan (Syamson \& Fadriyanto, 2018). Imunisasi TT bertujuan untuk mencegah terjadinya penyakit tetanus neonatorum pada bayi. Imunisasi merupakan bagian dari program Maternal and Neonatal Tetanus Elimination (MNTE) yaitu salah satu kegiatan imunisasi tambahan yang bertujuan untuk menurunkan jumlah kasus tetanus neonatal di setiap kabupaten hingga $<1$ kasus per 1000 kelahiran hidup pertahun (Maryono, 2010). Hasil penelitian (Indriaswuri, 2019) menunjukkan bahwa cakupan imunisasi pada Ibu Hamil yang belum mencapai target pemerintah, hal ini menggambarkan kepatuhan imunisasi TT Ibu Hamil masih sangat rendah. Rendahnya cakupan imunisasi TT pada Ibu Hamil berhubungan erat dengan kepatuhan Ibu Hamil terhadap imunisasi TT pada saat kehamilan. Namun kepatuhan Ibu Hamil dapat dipengaruhi oleh beberapa faktor. Menurut beberapa penelitian setelah dilakukan uji statistik kepatuhan imunisasi TT Ibu Hamil dipengaruhi oleh pengetahuan, pendidikan, media informasi, dukungan suami, dan ketersediaan obat dengan imunisasi tetanus toksoid dua pada Ibu Hamil trimester tiga (Maulida, 2012; Nurmawati \& Munawaroh, 2017).

Berdasarkan data hasil SDKI 2017, pemeriksaan kehamilan di Sulawesi Selatan secara garis besar ditunjukkan dengan persentase pemeriksaan kehamilan oleh tenaga kesehatan mencapai 98,3\% (Nasional 97,3\%), yang memperoleh imunisasi TT $\geq 2$ selama kehamilan sebesar 48,4\%, persentasi cakupan imunisasi TT di Provinsi Sulawesi Selatan masih lebih rendah dibandingkan cakupan imunisasi TT nasional sebesar 58\%. Persentase anak lahir hidup terakhir yang terlindung dari tetanus sebesar 77,5\% (SDKI, 2018). Menurut penelitian (Syamson \& Fadriyanto 2018), menunjukkan bahwa ada hubungan antara pengetahuan, sikap, dukungan keluarga imunisasi TT Ibu Hamil. Pada tahun 2018 dari 505 Ibu Hamil, jumlah Ibu Hamil yang 
mendapatkan imunisasi TT.1 sebanyak 74 orang Ibu Hamil dan TT.2 sebanyak 60 orang Ibu Hamil di Puskesmas Galesong (Puskesmas Galesong, 2018). Jumlah tersebut menunjukkan bahwa masih ada hal yang menjadi alasan jumlah Ibu Hamil belum menedapatkan imunisasi TT saat kehamilan. Tujuan penelitian mengetahui faktor yang memengaruhi kepatuhan imunisasi tetanus toksoid ibu hamil.

\section{Metode}

Jenis penelitian kuantitatif dengan desain penelitian yang digunakan dalam penelitian ini adalah Cross Sectional Study. Penelitian dilaksanakan pada bulan Januari - Feburari 2020 diwilayah kerja Puskesmas Galesong Kabupaten Takalar Provinsi Sulawesi Selatan. Populasi dalam penelitian ini adalah semua ibu hamil yang ada di wilayah kerja Puskesmas Galesong Kabupaten Takalar Provinsi Sulawesi Selatan sebanyak 505 Ibu Hamil. Teknik pengambilan sampel yang digunakan adalah non probability sampling dengan jumlah sebanyak 130 sampel yang memenuhi kreteria inklusi dengan menggunakan teknik pengambilan sampel menggunakan rumus Lemeshow. Pengumpulan data primer dan sekunder dengan menggunakan instrumen kuesioner. Pengolahan data; editing, coding, entry data dan cleaning data kemudian analisis data univariat dan bivariat dengan menggunakan program SPSS.

\section{Hasil Dan Pembahasan}

Tabel 1

Krakteristik Responden

\begin{tabular}{lcc}
\hline Kelompok Umur & Frekuensi & $\mathbf{\%}$ \\
\hline $15-24$ & 50 & 38,5 \\
\hline $25-34$ & 61 & 46,9 \\
\hline $35-44$ & 19 & 14,6 \\
\hline Jumlah & $\mathbf{1 3 0}$ & $\mathbf{1 0 0 , 0}$ \\
\hline Pendidikan & & \\
\hline Tidak Tamat SD & 3 & 2,3 \\
\hline Tamat SD & 35 & 26,9 \\
\hline Tamat SMP & 20 & 15,4 \\
\hline Tamat SMA & 71 & 54,6 \\
\hline Tamat PT & 1 & 0,8 \\
\hline Jumlah & $\mathbf{1 3 0}$ & $\mathbf{1 0 0 , 0}$ \\
\hline Sum: Data Primer & &
\end{tabular}

Sumber: Data Primer

Menunjukkan bahwa berdasarkan karakteristik responden di wilayah Kerja Puskemas Galesong, kelompok umur Ibu Hamil tertinggi pada kelompok umur 25-34 tahun yaitu sebesar 46,9\% dan terendah pada kelompok umur 35-44 tahun yaitu sebesar $14,6 \%$. Bahwa berdasarkan tingkat pendidikan, tertingi pada ibu dengan pendidikan terakhir tamat SMA yaitu sebesar 54,6\%, sedangkan yang terendah pada Ibu Hamil dengan pendidikan terakhir tamat PT yaitu sebesar $0,8 \%$. 
Jurnal Ilmiah Kesehatan Sandi Husada

Volume 10 Nomor 2 Desember 2021

Distribusi Responden berdasarkan Variabel

\begin{tabular}{|c|c|c|}
\hline Kepatuhan Imunisasi TT & Frekuensi & $\%$ \\
\hline Patuh & 97 & 74,6 \\
\hline Tidak Patuh & 33 & 25,4 \\
\hline Jumlah & 130 & 100,0 \\
\hline \multicolumn{3}{|l|}{ Akses Ke Fasyankes } \\
\hline Mendukung & 99 & 76,2 \\
\hline Tidak Mendukung & 31 & 23,8 \\
\hline Jumlah & 130 & 100,0 \\
\hline \multicolumn{3}{|l|}{ Pengetahuan } \\
\hline Cukup & 93 & 71,5 \\
\hline Kurang & 37 & 28,5 \\
\hline Jumlah & 130 & 100,0 \\
\hline \multicolumn{3}{|l|}{ Sikap } \\
\hline Cukup & 99 & 76,2 \\
\hline Kurang & 31 & 23,8 \\
\hline Jumlah & 130 & 100,0 \\
\hline \multicolumn{3}{|l|}{ Dukungan Suami } \\
\hline Cukup & 107 & 82,3 \\
\hline Kurang & 23 & 17,7 \\
\hline Jumlah & 130 & 100,0 \\
\hline \multicolumn{3}{|l|}{ Peran Petugas Kesehatan } \\
\hline Cukup & 102 & 78,5 \\
\hline Kurang & 28 & 21,5 \\
\hline Jumlah & 130 & 100,0 \\
\hline
\end{tabular}

Sumber: data primer

Menunjukkan bahwa berdasarkan distribusi variabel penelitian terhadap kepatuhan imunisasi TT Ibu Hamil di Wilayah Kerja Puskesmas Galesong menunjukkan bahwa ibu hami yang patuh imunisasi TT sebesar 74,6\% sedangkan yang tidak patuh sebesar 25,4\%. Menunjukkan bahwa berdasarkan akses, responden yang mengatakan akses mendukung sebesar $76,2 \%$ sedangkan yang mengatakan akses tidak mendukung sebesar $23,8 \%$. Menunjukkan bahwa berdasarkan pengetahuan, ibu dengan pengetahuan cukup sebesar 71,5\% sedangkan ibu dengan pengetahuan kurang sebesar 28,5\%. Menunjukkan bahwa berdasarkan sikap, sikap ibu cukup sebesar 76,2\% sedangkan sikap responden kurang sebesar 23,8\%. Menunjukkan bahwa berdasarkan dukungan suami, suami yang memberikan dukungan cukup sebesar 82,3\% sedangkan dukungan suami kurang sebesar17,7\%. Menunjukkan bahwa berdasarkan peran petugas kesehatan, responden yang mengatakan peran petugas kesehatan cukup sebesar 78,5\% sedangan responden yang mengatakan peran responden kurang sebesar $21,5 \%$. 
Tabel 2.

Analisis berdasarkan tentang hubungan antara variable

\begin{tabular}{|c|c|c|c|c|c|c|c|}
\hline \multirow{3}{*}{ Akses ke Fasyankes } & \multicolumn{6}{|c|}{ Kepatuhan Imunisasi TT } & \multirow{3}{*}{$\begin{array}{c}P- \\
\text { Value }\end{array}$} \\
\hline & \multicolumn{2}{|c|}{ Patuh } & \multicolumn{2}{|c|}{ Tidak Patuh } & \multicolumn{2}{|c|}{ Total } & \\
\hline & $\mathbf{f}$ & $\%$ & f & $\%$ & $\sum$ & $\%$ & \\
\hline Mendukung & 87 & 87,9 & 12 & 12,1 & 99 & 100 & \multirow{2}{*}{0,000} \\
\hline Tidak Mendukung & 10 & 32,3 & 21 & 67,7 & 31 & 100 & \\
\hline \multicolumn{8}{|l|}{ Pengetahuan } \\
\hline Baik & 67 & 72,0 & 26 & 28,0 & 93 & 100 & \multirow{2}{*}{0,285} \\
\hline Kurang & 30 & 81,1 & 7 & 18,9 & 37 & 100 & \\
\hline \multicolumn{8}{|l|}{ Sikap } \\
\hline Cukup & 82 & 82,8 & 17 & 17,2 & 99 & 100 & \multirow{2}{*}{0,000} \\
\hline Kurang & 15 & 48,4 & 16 & 51,6 & 31 & 100 & \\
\hline \multicolumn{8}{|l|}{ Dukungan Suami } \\
\hline Cukup & 89 & 83,2 & 18 & 16,8 & 107 & 100 & \multirow{2}{*}{0,000} \\
\hline Kurang & 8 & 34,8 & 15 & 65,2 & 23 & 100 & \\
\hline \multicolumn{8}{|l|}{ Peran Petugas } \\
\hline Cukup & 81 & 79,4 & 21 & 20,6 & 102 & 100 & \multirow{2}{*}{0,016} \\
\hline Kurang & 16 & 57,1 & 12 & 42,9 & 28 & 100 & \\
\hline
\end{tabular}

Sumber: data primer

Hasil uji statistic menggunakan uji chi-square diperolah nilai $\rho$ value $0,285>0,05$, sehingga Ho diterima. Hal tersebut berarti tidak ada hubungan yang bermakna antara pegetahuan dengan kepatuhan Ibu Hamil melaksanakan Imunisasi Tetanus Toksoid Ibu Hamil. Diperolah nilai $\rho$ value $0,285>0,05$, sehingga Ho diterima. Hal tersebut berarti tidak ada hubungan yang bermakna antara pegetahuan dengan kepatuhan Ibu Hamil melaksanakan Imunisasi Tetanus Toksoid Ibu Hamil. Diperolah nilai $\rho$ value $0,000<0,05$, sehingga Ha diterima. Hal tersebut berarti ada hubungan yang bermakna antara sikap dengan kepatuhan Ibu Hamil melaksanakan Imunisasi Tetanus Toksoid Ibu Hamil. Diperolah nilai $\rho$ value $0,000<0,05$, sehingga Ha diterima. Hal tersebut berarti ada hubungan yang bermakna antara dukungan suami dengan kepatuhan Ibu Hamil melaksanakan Imunisasi Tetanus Toksoid Ibu Hamil. Diperolah nilai $\rho$ value $0,0016<0,05$, sehingga Ha diterima. Hal tersebut berarti ada hubungan yang bermakna antara peran petugas kesehatan dengan kepatuhan Ibu Hamil melaksanakan Imunisasi Tetanus Toksoid Ibu Hamil.

\section{Pembahasan}

Hasil penelitian ini menunjukkan bahwa berdasarkan uji chi-square diperolah nilai $\rho$ value $0,000<0,05$, sehingga Ha diterima. Hal tersebut berarti ada hubungan yang bermakna antara akses dengan kepatuhan Ibu Hamil melaksanakan Imunisasi Tetanus Toksoid Ibu Hamil. Hal tersebut menunjukkan bahwa ada pengaruh akses terhadap kepatuhan Imunisasi Tetanus Toksoid Ibu Hamil. Peneliti berrasumsi bahwa kemudahan akses menuju tempat pelayanan akan memberikan dampak positif terhadap kemauan Ibu Hamil untu ke tempat pelayanan kesehatan memperoleh imunisasi TT. Ibu hami yang memiliki kendaraan pribadi akan lebih mudah ketika akan pergi dibandingkan harus menumpang atau naik kendaraan umum. Sebagian besar Ibu Hamil memiliki rasa malas yang tinggi untuk kemana-mana menggunakan kendaraan umum. Hasil 
Jurnal Ilmiah Kesehatan Sandi Husada

Volume 10 Nomor 2 Desember 2021

penelitian ini sejalan dengan penelitian yang dilakukan oleh Raidanti and Wahid (2019), menunjukkan bahwa ada hubungan yang bermakna antara aksesibilitas dengan pelaksanaan imunisasi TT.

Pengetahuan yang baik tidak selalu harus disertai dengan pendidikan yang tinggi namun kemauan untuk mencari informasi tentang imunisasi TT dengan dukungan petugas kesehatan yang aktif membantu menambah wawasan wanita usia subur khusunya Ibu Hamil tentang imunisasi TT. Sebagian besar responden menyadari bahwa imunisasi TT dapat mencegah infeksi tetanus toksoid pada bayi dan ibunya. Mereka juga sudah paham tujuan dari pemberian imunisasi TT. Hasil penelitian inu menunjukkan bahwa hasil uji chi-square diperolah nilai $\rho$ value $0,285>$ 0,05 , sehingga Ho diterima. Hal tersebut berarti tidak ada hubungan yang bermakna antara pegetahuan dengan kepatuhan Ibu Hamil melaksanakan Imunisasi Tetanus Toksoid Ibu Hamil. Hal tersebut berarti bahwa ibu dengan pengetahuan yang baik belum tentu patuh dalam memperoleh imunisasi TT. Hal ini dapat terjadi karena adanya faktor lain yang tidak mendukung seorang Ibu Hamil ketempat pelayanan untuk memperoleh imunisasi TT. Selain persoalan kesibukan pada saat jadwan imunisasi TT juga bisa dikarenakan faktor lain seperti akses dan dukungan keluarga.

Hasil penelitian ini sejalan dengan penelitian yang dilakukan oleh (Pebrianti, 2019) menunjukkan bahwa tidak terdapat hubungan antara pengetahuan dengan kelengkapan imunisasi tetanus toksoid di UPTD Puskesmas Alosika. Namun penelitian ini tidak sejalan dengan penelitian lain yang menemukan bahwa ada hubungan pengetahuan Ibu Hamil tentang imunisasi Tetanus Toksoid (TT) dengan perilaku kepatuhan imunisasi. Pengetahuan Ibu Hamil memengaruhi perilaku kepatuhan dalam melakukan imunisasi TT. Jika pengetahuan baik maka akan meningkatkan perilaku kepatuhan Ibu Hamil (Tillatul, 2017). Perbedaan ini dapat dikarenakan oleh beberapa faktor penunjang lainnya. Faktor-faktor lain yang dapat memengaruhi adalah dukungan petugas kesehatan dan dukungan keluarga terutama dukungan suami. Sehingga sangat penting untuk mengontrol hal pendukung lainnya yang dapat meningkatkan kepatuhan Ibu Hamil untuk melengkapi imunisasi TT mereka, karena dengan pengetahuan saja tidak cukup untuk meningkatkan kepatuhan Ibu Hamil untuk melakukan suntik imunisasi TT. Perlunya juga meningkatkan motivasi Ibu Hamil untuk hadir ke tempat pelayanan dengan memberikan hal-hal menarik seperti kegiatan yang dapat memberikan Ibu Hamil semangat. Menurut (Melani \& Barokah, 2020) bahwa pengetahuan tentang manfaat, jadwal efek samping dan kontraindikasi kontrasepsi, dan kurangnya pengetahuan tentang indikasi.

Sikap merupakan reaksi atau respon yang masih tertutup dari seseorang terhadap stimulus atau objek. Sikap secara nyata menunjukkan konotasi adanya kesesuian reaksi terhadap stimulus tertentu yang dalam kehidupan sehari-hari merupakan reaksi yang bersifat emosional terhadap stimulus sosial. Sikap memiliki beberapa tingkatan yaitu menerima, merespon, menghargai, dan bertanggung jawab (Aini, 2009). Sikap merupakan kesiapan atau kesediaan untuk bertindak. Sikap tidak dapat langsung dilihat tetapi hanya dapat ditafsirkan dahulu dan perilaku tertutup. Sikap mempunyai tiga komponen yaitu: kepercayaan / keyakinan, keluarga dan konsep terhadap suatu objek kehidupan emosional atau evaluasi emosional terhadap suatu objek, kecendrungan emosional untuk bertindak (Notoatmodjo, 2003). Ibu Hamil sebagian besar setuju dengan adanya program imunisasi TT, karena mereka juga sudah memahami bahwa imunnisasi TT dapat membantu mencegah dari penyakit infeksi tetanus toksoid pasca persalinan yang bisa terjadi pada ibu dan bayinya. Pernyataan setuju Ibu Hamil terhadap banyaknya manfaat imunisasi TT cukup besar. Ibu Hamil dengan sikap baik yang patuh imunisasi TT lebih besar dibandingkan Ibu Hamil dengan sikap kurang yang patuh imunisasi TT. Hasil uji statistik menggunakan chi-square diperolah nilai $\rho$ value $0,000<0,05$, sehingga Ha diterima. Hal tersebut berarti ada hubungan yang bermakna antara sikap dengan kepatuhan Ibu Hamil melaksanakan Imunisasi Tetanus Toksoid Ibu Hamil.

Penelitian ini sejalan dengan penelitian yang dilakukan oleh Suhartatik and Mato (2018), menunjukkan bahwa ada hubungan antara sikap dengan imunisasi tetanus toksoid wanita usia 
subur. Menurut asumsi peneliti, sikap yang positif sangat diperlukan bagi wanita usia subur dalam pemberian imunisasi TT karena dengan adanya sikap yang positif maka Ibu Hamil akan menerima informasi tentang imunisasi TT dan akan berusaha supaya dapat merasakan manfaat dari imunisasi TT tersebut, sehingga Ibu Hamil mau patuh menjalankan imunisasi TT secara lengkap.

Namun hasil penelitian ini tidak sejalan dengan penelitian Mahyuni, Noor and Yunidai (2015), menyatakan bahwa tidak ada hubungan yang bermakna antara sikap dengan kelengkapan imunisasi TT Ibu Hamil. Hasil penelitian yang dilakukan oleh Manurung (2018), menunjukkan bahwa sikap tidak mempunyai hubungan terhadap tindakan imunisasi tetanus toksoid. Ibu Hamil yang bersikap positif maupun negatif tidak ada hubungan dengan kelengkapan imunisasi TT, karena walaupun seseorang mempunyai sikap yang positif tetapi perilakunya terhadap kepatuhan untuk imunisasi TT secara lengkap masih kurang maka pencapaian program imunisasi TT2 di puskesmas Lokbaintan masih rendah. Hal ini dikarenakan kebanyakan Ibu Hamil malas dikarenakan jarak ke fasilitas kesehatan yang jauh, petugas kesehatan yang jarang ada di tempat. Sehingga diharapkan adanya kerjasama yang baik antara petugas kesehatan dengan masyarakat, kerja sama lintas program dengan poli KIA dan sektor lainnya dalam upaya peningkatan cakupan imunisasi TT.

Ibu Hamil dengan dukungan suami baik maka Ibu Hamil yang patuh memperoleh imunisasi TT lebih besar dibandingkan Ibu Hamil dengan dukungan suami kurang. Hasil uji statistik menggunakan chi-square diperolah nilai $\rho$ value $0,000<0,05$, sehingga Ha diterima. Hal tersebut berarti ada hubungan yang bermakna antara dukungan suami dengan kepatuhan Ibu Hamil melaksanakan Imunisasi Tetanus Toksoid Ibu Hamil.

Penelitian ini sejalan dengan penelitian yang dilakukan oleh Lumbantobing (2019) menunjukkan bahwa terdapat hubungan dukungan keluarga dengan kepatuhan Ibu Hamil melakukan imunisasi TT. Dukungan keluarga merupakan suatu strategis intervensi preventif yang paling baik dalam membantu anggota keluarga mengakses dukungan sosial yang belum digali untuk sesuai strategis bantuan yang bertujuan untuk meningkatkan dukungan keluarga yang adekuat. Menurut asumsi peneliti diperlukan suatu dorongan dari keluarga dalam melakukan imunisasi TT karena dengan adanya dukungan dari keluarga, maka seorang ibu merasa diberikan dorongan untuk dapat meningkatkan kepatuhan dalam melakukan imunisasi TT. Faktor dukungan keluarga juga memegang peranan yang penting, sama halnya dengan pengetahuan dan sikap dari ibu. Tanpa adanya dukungan dari keluarga maka kepatuhan seorang Ibu Hamil dalam melakukan imunisasi tidak berjalan dengan kemauan Ibu Hamil. Hasil penelitian ini memberikan informasi kepada peneliti bahwa sebaiknya yang memperoleh edukasi dalam hal imunisasi TT bukan hanya untuk Ibu Hamil saja, namun suami juga harus memperoleh lebih banyak informasi tentang manfaat dan pentingnya terpenuhinya imunisasi TT sehingg dukungan yang besar dari suami akan memberikan dorongan kepada Ibu Hamil untu meningkatkan kepatuhan dalam melengkapi imunisasi TT. Pembangunan kesehatan adalah suatu cara untuk meningkatkan kesadaran, kemauan dan kemampuan hidup sehat bagi setiap orang agar tercapai derajat kesehatan masyarakat yang optimal (Suprapto \& Lalla, 2021).

Hasil penelitian ini menunjukkan bahwa Ibu Hamil yang merasakan peran petugas kesehatan baik yang patuh imunisasi TT sebesar 79,4\%, sedangkan Ibu Hamil yang merasakan peran petugas kesehatan kurang yang patuh imunisasi TT sebesar 57,1\%. Hasil uji 353egative 353 menggunakan chi-square diperolah nilai $\rho$ value $0,016<0,05$, sehingga Ha diterima. Hal tersebut berarti ada hubungan yang bermakna antara peran petugas kesehatan dengan kepatuhan Ibu Hamil melaksanakan Imunisasi Tetanus Toksoid Ibu Hamil.

Penelitian ini sejalan dengan penelitian yang dilakukan oleh (Syaida, 2017) menunjukkan bahwa ada hubungan antara peran tenaga kesehatan dengan status imunisasi tetanus toksoid (TT) pada wanita usia subur. Apabila petugas kesehatan meningkatkan lagi kunjungan dan edukasi kepada Ibu Hamil diharapkan hal tersebut dapat membantu meningkatnya kepatuhan imunisasi TT Ibu Hamil, sehingga cakupan imunisasi TT dapat mencakup semua Ibu Hamil. Kerja sama 
Jurnal Ilmiah Kesehatan Sandi Husada

Volume 10 Nomor 2 Desember 2021

antara petugas kesehatan, Ibu Hamil, pihak keluarga khususnya suami serta akses yang memadai akan sangat memungkinkan untuk tercapainya cakupan imunisasi TT yang maksimal.

\section{Simpulan Dan Saran}

Bahwa ada pengaruh sikap, akses ke fasyankes, dukungan suami dan peran petugas kesehatan terhadap kepatuhan Ibu Hamil melaksanakan Imunisasi Tetanus Toksoid sedangkan pengetahuan tidak mempengaruhi Ibu Hamil dalam melaksanakan Imunisasi Tetanus Toksoid. Perlunya meningkatkan akses Ibu Hamil untuk ketempat fasilitas kesehatan untuk memperoleh imunisasi TT seperti kondisi jalan yang baik, zona jaran antara tempat pelayanan kesehatan dengan rumah masyarakat di pertimbangkan sehingga semua Ibu Hamil merasa dekat saat akan ke tempat pelayanan kesehatan

\section{Daftar Rujukan}

Aini, M. (2009). Faktor-Faktor Yang Berhubungan Dengan Tingkat Partisipasi Ibu Dalam Pemberian Imunisasi Dasar Di Wilayah Kerja Puskesmas Puskesmas Ujan Mas Kabupaten Muara Enim Tahun 2008. STIK Palembang.

Depkes RI. (2010). Imunisasi Edisi Ketujuh.

Indriaswuri, A. (2019). Gambaran Cakupan Pemberian Imunisasi Tetanus. Univeristas Muhammadiyah Surakarta.

Kemenkes RI. (2012). Eliminasi Tetanus Maternal dan Neonatal (MNTE) di Indonesia. In Sekretaris Jendral Kemkes RI (Vol. 66). Kementerian Kesehatan RI.

Lumbantobing, C. N. (2019). Determinan Pemanfaatan Imunisasi TT pada Ibu Hamil di Wilayah Kerja Puskesmas Simalingkar Medan Tahun 2018.

Mahyuni, A., Noor, M., \& Yunidai, F. (2015). Hubungan Pengetahuan Dan Sikap Ibu Hamil Dengan Kelengkapan Imunisasi Tetanus Toksoid (TT) Di Puskesmas Lokbaintan Tahun 2013. Jurkessia, Vol 5 No 2, 25-31.

Manurung, O. (2018). Hubungan Faktor Predisposisi Terhadap Tindakan Imunisasi Tetanus Toksoid Pada Ibu Hamil Di Wilayah Kerja Puskesmas Pancur Batu Tahun 2017. Jurnal Ilmiah Kohesi, 2(1).

Maryono. (2010). Pengaruh Kompetensi Petugas Imunisasi Terhadap Pelayanan Imunisasi Tetanus Toxoid Pada Wanita Usia Subur (Wus) Di Kabupaten Aceh Barat Provinsi Nanggroe Aceh Darussalam. Universitas Sumatera Utara.

Maulida, S. W. (2012). Faktor-Faktor Mempengaruhi Cakupan Imunisasi Tetanus Toksoid pada Ibu Hamil di Wilayah Kerja Puskesmas Meutulang Kecamatan Panton Reu Kabupaten Aceh Barat Tahun 2012. Jurnal Kesehatan Masyarakat.

Melani, F., \& Barokah, L. (2020). Knowledge Women of childbearing age About Pill Contraception. Jurnal Ilmiah Kesehatan Sandi Husada, 9(2 SE-Articles). https://doi.org/10.35816/jiskh.v12i2.456

Notoatmodjo, S. (2003). Pendidikan dan perilaku kesehatan. Jakarta: Rineka Cipta, 16, 15-49.

Nurmawati, \& Munawaroh. (2017). Faktor-faktor yang berhubungan dengan imunisasi tetanus toksoid dua (TT2) pada Ibu Hamil Trimester Tiga di Puskesmas Kemuning Desa Cimanggis Kecamatan Bojong Gede Kabupaten Bogor Provinsi Jawa Barat 2016. Jurnal Ilmu Dan Budaya, 40(55).

Pebrianti. (2019). Hubungan Pengetahuan Dengan Kelengkapan Imunisasi Tetanus Toksoid Pada Ibu Hamil Trimester Iii Di Uptd Puskesmas Alosika. Jurnal Kebidanan Vokasional, 4(1), 45-49. https://doi.org/10.35892/JKV.V4I1.224

Puskesmas Galesong. (2018). Profil Puskesmas Galesong Tahun 2017. Puskesmas Galesong.

Raidanti, D., \& Wahid. (2019). Hubungan Aksesibilitas, dukungan tenaga kesehatan dan ersepsi terhadap pelaksanaan imuniasasiTT Pra Nikah di Puskesmas Sukamulya Kecamatan Sukamulya Kab. Tanggerang Tahun 2017. Jurnal Ilmiah Kesehatan Delima, 1(1), 1-13. https://doi.org/10.1017/CBO9781107415324.004

SDKI. (2018). Survey Demografi dan Kesehatan Indonesia. In Survei Demografi dan Kesehatan Indonesia. Badan Kependudukan dan Keluarga Berencana Nasional. 
https://doi.org/0910383107 [pii]ไr10.1073/pnas.0910383107

Suhartatik, S., \& Mato, R. (2018). Faktor Yang Berhubungan Dengan Imunisasi Tetanus Toksoid Pada Wanita Usia Subur Di Puskesmas Mandai Kabupaten Maros. Media Keperawatan: Politeknik Kesehatan Makassar, 9(1), 1-10.

Suprapto, T. C. M., \& Lalla, N. S. N. (2021). Nurse competence in implementing public health care. International Journal of Public Health, 10(2), 428-432.

Suryati, E. (2015). Hubungan Pengetahuan dan Sikap ibu Hamil dengan Pemberian Imunisasi Tetaanus Toksoid di Wilayah Kerjaa Puskesmas Maga Kecmatan Lembah Sorik Maraapi Kabupaten Mandailing Natal. Universitas Sumatra Utara.

Syaida, R. (2017). Hubungan Peran Petugas Kesehatan Dengan Status Imunisasi Tt Pada Wanita Usia Subur Di Puskesmas Danurejan I Yogyakarta. Kesehatan, 10.

Syamson \& Fadriyanto. (2018). Faktor yang Berhubungan Dengan Pemberian Imunisasi Tetanus Toxoid (TT) Pada Ibu Hamil Di Wilayah Kerja Puskesmas Rappang Kabupaten Sidrap Tahun 2017. Jurnal Ilmiah Kesehatan Diagnosis, 12(2), 177-181.

Tillatul, L. (2017). Hubungan Pengetahuan Ibu Hamil Tentang Imunisasi Tetanus Toksoid (Tt) Dengan Perilaku Kepatuhan Imunisasi Di Puskesmas Gayam Sapudi Kabupaten Sumenep. Universitas Muhammadiyah Malang. 